Megas, Georgios A.; Anna Angelopoulos; Aigli Brouskou; Marianthi KAPlanogloU; Emmanouela KATRINAKI: Catalogue of Greek Magic Folktales. Folklore Fellows' Communications 303. Hèlsinki: Suomalainen Tiedeakatemia, 2OI2, $350 \mathrm{p}$.

\title{
Catalogue of Greek Magic Folktales
}

Jaume GUISCAFRÈ DANÚS

Universitat de les Illes Balears, Palma

El propòsit discret amb què les autores presenten aquesta obra — «We hope that this Catalogue of Greek Magic Folktales, in both its Greek and English editions, will serve as a useful tool for future comparative research» (p. I9) - no revela amb gaire exactitud el que conté. D'entrada, és un catàleg —és a dir, una eina, i molt útil, per cert-, però és molt més que un catàleg: és una molt bona mostra de capacitat crítica, de sagacitat analítica, de domini dels conceptes teòrics i de la bibliografia i d'un coneixement profund de l'objecte d'estudi. No debades es tracta d'una versió abreujada, condensada i traduïda a l'anglès dels cinc volums que les quatre responsables del projecte ja havien publicat anteriorment en grec, el primer dels quals havia aparegut també en traducció francesa. ${ }^{\mathrm{I}}$ Amb aquesta edició en anglès, i en una col-lecció tan prestigiosa com la Folklore Fellows' Communications, els especialistes en la catalogació del conte oral i els lectors interessats en la rondalla meravellosa en general tenen ara al seu abast una obra de referència obligada.

El volum s'obre amb un prefaci (p. I3-I9) en què l'equip editorial, d'una banda, dóna compte de manera sumària però suficient de les vicissituds per què ha passat el projecte de catalogació del conte oral grec i en què, d'altra banda, explica les tres fases de la recerca que han precedit la publicació del catàleg: la recol-lecció dels materials, la classificació de les versions i el mètode d'anàlisi i de presentació dels resultats.

L'origen d'aquest volum, de fet, es remunta a I9Io, quan Nikolaos Politis va encarregar a Georgios A. Megas l'elaboració d'un catàleg del conte grec basat en el sistema de classificació que Antti Aarne tot just havia donat a conèixer aquell mateix any. ${ }^{2}$ Tot i la quantitat ingent de materials que va arribar a reunir i a estudiar, Megas només va arribar a publicar, l'any 1978, el primer volum del catàleg,

I. Angelopoulos, Anna; Aigli Brouskou (1994): Epexergasia paramythiakon typon kai parallagon AT 700-749. G. Megas Katalogos Ellinikon Paramython - 2. Athena: Historiko Archeio Ellinikis Neolaias / Geniki Grammateia Neas Genias; ANGElopoulos, Anna; Aigli BROUSKOU (1995): Catalogue raisonné des contes grecs: types et versions AT 700-749. Athènes: Archives Historiques de la Jeunesse Grecque / Centre de Recherches Néohelléniques; Angelopoulos, Anna; Aigli Brouskou (I999): Epexergasia paramythiakon typon kai parallagon AT 300-499. G. Megas Katalogos Ellinikon Paramython-3. 2 vols. Athena: Historiko Archeio Ellinikis Neolaias / Geniki Grammateia Neas Genias; ANGelopoulos, Anna; Marianthi KAPLANOGLOU; Emmanouela KATRINAKI (2004): Epexergasia paramythiakon typon kai parallagon AT 50o-559. G. Megas Katalogos Ellinikon Paramython - 4. Athena: Historiko Archeio Ellinikis Neolaias / Geniki Grammateia Neas Genias; ANGelopoulos, Anna; Marianthi KAPLANOGLOU; Emmanouela KATRINAKI (2007): Epexergasia paramythiakon typon kai parallagon AT 560-699. G. Megas Katalogos Ellinikon Paramython - 5. Athena: Historiko Archeio Ellinikis Neolaias / Geniki Grammateia Neas Genias.

2. AARne, Antti (I9IO): Verzeichnis der Märchentypen. Folklore Fellows' Communications 3. Hèlsinki: Suomalainen Tiedeakatemia. 
dedicat a les rondalles d'animals. Els documents inèdits que va llegar, en morir, a Mihalis G. Meraklis són el punt de partida del treball excel-lent que han dut ha terme Angelopoulos, Brouskou, Kaplanoglou i Katrinaki.

El gruix del llibre (p. 20-333), naturalment, l'ocupa el catàleg dels tipus en què les autores han classificat les versions de rondalles meravelloses gregues que Megas havia compilat i que inclouen materials documentats o enregistrats - en grec o en altres llengües - entre mitjan segle XIX i la primera meitat de la dècada dels anys setanta del segle $\mathrm{xx}$, no solament en el territori que configura la Grècia actual, sinó també en els territoris en què la cultura i la llengua gregues tenen o han tingut una presència més o menys persistent —el sud d'Itàlia, Xipre, l'Àsia Menor, el Pont i la Capadòcia.

L'equip editorial ha classificat aquests materials i n'ha establert els tipus en bona manera a partir de les indicacions i les propostes que Megas mateix havia deixat escrites i que Aarne i Thompson va incorporar de manera parcial. ${ }^{3}$ Tot i aquest principi, però, se n'ha apartat o n'ha refet les propostes d'adscripció tipològica quan ho han exigit els resultats de les recerques, les aportacions crítiques d'altres catalogadors i folkloristes o l'edició revisada del catàleg internacional. ${ }^{4}$ Qualsevol que tingui una mínima experiència en la classificació i la catalogació de contes orals sap prou bé que no sempre és fàcil arribar a un consens sobre quina és l'adscripció tipològica més escaient per a cada versió concreta. Per tant, no ha de venir de nou que el resultat final d'aquesta fase d'ordenació i de classificació de les versions compilades posi en evidència les tensions que, de manera inevitable, es produeixen sempre entre el catàleg internacional i els diversos catàlegs nacionals. Aquest fet, però, no s'hauria d'entendre com una desautorització sistemàtica del primer, sinó més aviat com un aval que el confirma com un referent prou sòlid que permet correccions, ampliacions i modificacions en funció dels resultats de les recerques que menen a la construcció dels segons. Així, les discrepàncies respecte de les propostes de classificació prèvies s'hi concreten fonamentalment en tres aspectes: el canvi d'adscripció tipològica d'algunes versions, la renumeració i, doncs, la reubicació d'alguns tipus que ja figuren en el catàleg internacional de referència i la proposta de creació de dinou tipus que el catàleg internacional no preveu - ${ }^{*} 3 \mathrm{I} 6 \mathrm{~A},{ }^{*} 33 \mathrm{IA},{ }^{*} 4 \mathrm{II},{ }^{*} 46 \mathrm{OB},{ }^{*} 48 \mathrm{O},{ }^{*} 5 \mathrm{O} 7 \mathrm{D}$, *884C, *884D, *5I $4 \mathrm{~A},{ }^{*} 5 \mathrm{I} 4 \mathrm{~B}$, ${ }^{*} 5 \mathrm{I} 4 \mathrm{C},{ }^{*} 546 \mathrm{~A},{ }^{*} 6 \mathrm{I} 3 \mathrm{D},{ }^{*} 6 \mathrm{I} 3 \mathrm{E},{ }^{*} 654,{ }^{*} 667 \mathrm{~A},{ }^{*} 667 \mathrm{~B},{ }^{*} 735 \mathrm{E} \mathrm{i}$ *742- a partir de la identificació i l'anàlisi prèvies dels ecotips grecs; algun d'aquests ecotips proposats, per cert, també tenen presència en altres tradicions narratives, com el *480 The Two Old Women and the Twelve Months, del qual hi ha tres versions documentades en la rondallística catalana i una - la d'Alcover- duu precisament el títol de «Dotze mesos i dues jaies». ${ }^{5}$

Un cas molt patent de discrepància respecte del catàleg internacional és el que afecta els tipus que conformen el cicle de Psique i Eros o de l'espòs transformat. Uther (2004) ja va reordenar profundament els tipus que l'integren i va reduir a vuit $-425,425 \mathrm{~A}, 425 \mathrm{~B}, 425 \mathrm{C}, 425 \mathrm{D}, 425 \mathrm{E}, 425 \mathrm{M}$ i $425^{*}$ - els setze que preveuen

3. Aarne, Antti; Stith Thompson (I96I): The Types of the Folktale. Folklore Fellows' Communications 284. Hèlsinki: Suomalainen Tiedeakatemia.

4. UtHer, Hans-Jörg (2004): The Types of International Folktales. Part I. Folklore Fellows' Communications I84. Hèlsinki: Suomalainen Tiedeakatemia.

5. Oriol, Carme; Josep M. Pujol (2008): Index of Catalan Folktales. Folklore Fellows' Communications 294. Hèlsinki: Suomalainen Tiedeakatemia. 
Aarne i Thompson (I96I). Les autores del catàleg grec, però, es distancien d'aquestes dues classificacions i opten per oferir-ne una de pròpia a partir de la proposta de Megas i tornen a ampliar el nombre de tipus fins a catorze $-425,425 \mathrm{~A}, 425 \mathrm{~B}$, $425 \mathrm{C}, 425 \mathrm{D}, 425 \mathrm{E}, 425 \mathrm{~F}, 425 \mathrm{G}, 425 \mathrm{~K}, 425 \mathrm{~L}, 425 \mathrm{P}, 425 \mathrm{R}, 425 \mathrm{Ra}$ i $425 \mathrm{X}$. Aquesta nova expansió es justifica perquè «all these narratives have kept their own characteristics; their plots are rich, autonomous, and thus impossible to integrate into the proposed new tale types. [...] by keeping them we allow a better understanding as well as a thorough analysis of the Greek oral tradition» (n. I36, p. IIo). Sembla, però, que no s'aplica un criteri uniforme en la resolució d'aquestes dissensions. Per exemple, les autores afirmen, de manera una mica sorprenent, que els tipus 330 The Man Deceives Death (the Devil) i 33I The Devil in the Bottle «could also be included in the cycle of anecdotes and jokes, since the narrators make fun of the most tragic thing in human life, death itself» (p. 8I) o qüestionen, de manera ben argumentada, l'adscripció del tipus 555 The Fisherman and His Wife al gènere de la rondalla meravellosa; però tant en un cas com en l'altre mantenen els tipus en les ubicacions actuals. En canvi, proposen els tipus nous *5I4A The Old Woman Who Was Skinned i 7IOB The Ghoulish Schoolmaster per adscriure-hi les versions que actualment solen ubicar-se sota el tipus ATU 877 The Old Woman Who Was Skinned i ATU 894 The Ghoulish Schoolmaster and the Stone of Pity, cosa que implica haver de reubicar les versions dels dos relats del gènere de la rondalla d'enginy al gènere de la rondalla meravellosa, que certament els és molt més adequat.

La informació relacionada amb cada tipus hi apareix estructurada d'aquesta manera: número; títol, que no necessàriament coincideix amb els que els donen Aarne i Thompson (I96I) o Uther (2004); una síntesi, seguida del nombre i de la seva distribució geogràfica, de les versions que s'hi adscriuen; una llista de les que han estat traduïdes a altres idiomes, i un apartat final de comentaris. En comptes d'oferir-ne un resum argumental o una descripció episòdica amb indicació dels motius més importants, que solen ser les pràctiques més habituals en aquesta mena de catàlegs, l'equip editorial ha optat per seguir el mètode de presentació dels tipus de Delarue i Tenèze i, per tant, presenta una versió sintètica de la història en què es combinen l'estructura episòdica i la llista detallada dels elements que virtualment en poden integrar el relat. ${ }^{6} \mathrm{Si}$ bé és cert que aquesta solució enfarfega una mica la lectura de les descripcions, té l'avantatge que «allows to understand the flow of the narrative and the sequence of events, but at the same time shows all the possibilities of the story's composition» (p. I7), que al cap i a la fi és la informació que pot interessar més els especialistes.

A parer meu, però, l'aportació més destacable que ofereix aquest catàleg són els comentaris amb què es clou la presentació dels tipus i que fa que sigui, pròpiament, un catàleg raonat. L'equip editorial s'hi ha esforçat per oferir al lector els arguments i els recursos en què fonamenta teòricament i de manera sòlida les solucions catalogràfiques que hi pren, però també hi tracta aspectes relacionats amb el contingut i la interpretació dels relats i d'altres que posen en relleu els lligams que les versions que s'adscriuen al tipus mantenen amb l'entorn geogràfic i social en què s'han documentat. Per exemple, a propòsit del 480B The Good Girl and the Bad Girl at the Mill —un tipus que ni Aarne i Thompson (I96I) ni Uther (2004) no

6. Delarue, Paul; Marie-Louise Tenèze (2002): Le conte populaire français. París: Maisonneuve $\&$ Larose. 
preveuen de manera explícita i del qual s'han documentat trenta versions-, s'hi remarca que «has become very popular in these areas of diffusion where it was associated with a specific social context, the groups of women who gathered for a female collective work» (p. I56). Les autores, d'altra banda, fan seva la premissa que la majoria de tipus narratius estan interrelacionats amb altres i hi constitueixen cicles i que els narradors els actualitzen en un procés constant de combinació i d'hibridació. En aquest sentit, és molt lloable l'esforç teòric que hi han fet perquè el catàleg reflecteixi tant com sigui possible les dinàmiques socials en què es mou el conte oral, un propòsit que enuncien de manera inequívoca al prefaci: «The catalogue aims a theoretical approach to tale-telling as a living and dynamic process within the context of modern Greek society» (p. I8). Aquest plantejament - molt encertat, d'altra banda - té conseqüències sobre l'organització dels tipus i dels comentaris que hi estan associats: els tipus s'hi solen presentar agrupats en funció de les afinitats temàtiques i estructurals que tenen i s'hi solen comentar conjuntament. Per aquesta raó, per exemple, els tipus *884C The Girl as Soldier i *884D The King with Three Sons and the King with Three Daughters, que pertanyen al gènere de la rondalla d'enginy, s'inclouen en el catàleg just darrere del tipus 5I4 The Shift of Sex.

El llibre es tanca amb una nodrida llista que conté les referències bibliogràfiques que se citen en el prefaci i en el cos de l'obra (p. 334-346) i amb una altra llista en què es detallen els títols i els números corresponents a cada tipus (p. 347-350).

Ja per acabar, i en vista dels resultats esplèndids que ofereix aquest Catalogue of Greek Magic Folktales, esperem que l'equip editorial que l'ha dut a terme continuï la tasca d'anàlisi i de catalogació de les versions que corresponen als altres gèneres rondallístics a fi que en una data no gaire llunyana el catàleg complet del conte oral grec pugui ser una realitat. 